\title{
Potentiation of $N$-Methyl-D-Aspartate-Mediated Brain Injury by a Human Immunodeficiency Virus-1-Derived Peptide in Perinatal Rodents ${ }^{1}$
}

\author{
JOHN D. BARKS, MADHAVAN P. N. NAIR, STANLEY A. SCHWARTZ, AND \\ FAYE S. SILVERSTEIN \\ Departments of Pediatrics [J.D.B., M.P.N.N., S.A.S., F.S.S.], and Neurology [F.S.S.], University of Michigan. \\ Ann Arbor, Michigan 48109; and Department of Medicine. State University at New York, Buffalo, New' \\ York 14203 [M.P.N.N., S.A.S.]
}

\begin{abstract}
In this study, we tested the hypothesis that human immunodeficiency virus (HIV)-1-derived peptides augment the neurotoxicity of excitatory amino acid agonists in vivo in postnatal day (PND) 7 rats. Stereotaxic intracerebral injections of the excitatory amino acid agonist $N$-methyl-D-aspartate (NMDA), alone or coinjected with an HIV-derived recombinant fusion peptide envelope gag (env-gag) were performed in PND-7 rats [group I: 5 nmol NMDA, $n=20$; group II: 5 nmol NMDA + low-dose (1 or 50 ng) env-gag, $n=27$; group III: 5 nmol NMDA + high-dose (100 ng) env-gag, $n=20$, and brain injury was evaluated on PND 12. Based on histopathology scoring and measurements of hippocampal cross-sectional areas in the injected and contralateral hemispheres, coinjection of $100 \mathrm{ng}$ of env-gag with $5 \mathrm{nmol}$ of NMDA markedly increased the severity of resulting injury $(p<0.002$, comparing histopathology scores; $p<0.003$, comparing interhemispheric differences in hippocampal areas). These data suggest that in the developing nervous system HIV neurotoxicity may result, at least in part, from overactivation of excitatory amino acid receptors, and that perinatal rodent models may provide clinically relevant insights about the pathophysiology of HIV-mediated brain injury. (Pediatr Res 34: 192-198, 1993)
\end{abstract}

\section{Abbreviations}

EAA, excitatory amino acid

HIV, human immunodeficiency virus

NMDA, $\boldsymbol{N}$-methyl-D-aspartate

env-gag, envelope-gag

PND, postnatal day

Current estimates suggest that 25 to $40 \%$ of infants born to HIV-infected women develop clinical and/or serologic evidence of HIV infection in the first year of life (1), and progressive encephalopathy is a prominent and devastating complication of congenital HIV infection (2). Relatively little is known about the cellular and molecular mechanisms that cause neuronal injury

Received January 29, 1993; accepted March 30, 1993.

Correspondence: F. S. Silverstein, M.D., University of Michigan, Room 6028. Kresge II Bldg.. Ann Arbor, MI 48109-0570.

Supported by a grant from the Pediatric AIDS Foundation of the American Foundation for AIDS Research (F.S.S. and J.D.B.) and USPHS IROIMH42988 (S.A.S.).

Preliminary reports of these data were presented at the annual meetings of the Society for Pediatric Research, Baltimore, MD, May 1992, and the Society for Neuroscience, October 1992. in HIV-infected patients, or about factors that accelerate neurodegeneration.

Several recent studies, based on in vitro analysis of the neurotoxicity of HIV and its constituent envelope protein $\mathrm{gp} 120$, suggested a novel mechanism of HIV-induced neuronal injury, caused by increased activation of NMDA-type EAA receptors (3-5). In vitro HIV-infected macrophages secrete factors that cause histologic and neurochemical damage to cultured rodent and human neurons (5). Giulian et al. (4) found that the in vitro neurotoxicity of HIV-infected macrophages, mediated by secreted, heat-stable, toxic factor(s), could be blocked by the competitive NMDA antagonist amino-phosphonovaleric acid and the noncompetitive NMDA antagonist MK-801. Gp120 itself is also toxic to retinal ganglion cells and hippocampal neurons in vitro (4). Lipton et al. found that the neurotoxic properties of the HIV envelope protein gp 120 could be blocked by depleting rat retinal cell cultures of glutamate (the endogenous agonist for NMDA receptors); of note, they also found that gp 120 exerted no obvious direct effects on NMDA-activated membrane currents, thus suggesting that gp 120 neurotoxicity was mediated by synergism with endogenous glutamate (6). Together, these observations provide support for the hypothesis that HIV-derived peptides may cause neuronal injury by an indirect mechanism related to EAA receptor activation (7).

Considerable data indicate that developmental stage is a critical determinant of susceptibility to EAA-mediated neurotoxicity, and the immature brain is more susceptible to the neurotoxic properties of NMDA than is the adult brain (8). This heightened susceptibility may be related to a higher NMDA receptor density, to immaturity of adaptive mechanisms for buffering rises in intracellular calcium, to altered sensitivity of NMDA receptors to regulation by magnesium and glycine, or to expression of unique NMDA receptor subtypes at this developmental stage.

Because susceptibility to NMDA-induced neuronal injury peaks in the developing brain, we selected a well-characterized animal model of perinatal excitotoxic brain injury to examine the impact of HIV-derived factors on EAA-mediated neurotoxicity in vivo. Although the underlying molecular mechanisms are uncertain, the defined range of bioactivity of synthetic HIV. derived peptide fragments continues to expand. We selected envgag, a bioactive, recombinant fusion HIV-derived peptide, for testing (9). [Env-gag was provided (to M.P.N.) by HoffmannLaRoche, Nutley, NJ.] Env-gag, which incorporates epitopes from both envelope and core HIV proteins, was initially developed as a diagnostic reagent. It is expressed in Escherichia coli and consists of an 80-amino acid sequence from gp 41 (env 560639), a 190-amino acid sequence from p24 (gag 87-276), and a 21 -amino acid vector peptide sequence. It has been used successfully as a screening peptide to evaluate potential mechanisms of HIV-induced immunodeficiency. Env-gag possesses potent 
immunoregulatory activity in a variety of in vitro assays (9) [as do several other synthetic and recombinant HIV-derived peptides $(10-12)]$. We found that coinjection of env-gag with NMDA markedly increased the severity of resulting brain injury, in comparison with littermates that received the same dose of NMDA alone.

\section{MATERIALS AND METHODS}

Animal lesioning. Direct intracerebral injection provided the optimal method of drug delivery because much smaller doses could be administered than would be used systemically, the issue of blood-brain barrier permeability was obviated, and side-toside comparisons of tissue integrity could be done. All injections were done [by a single individual (J.D.B.)] in ether-anesthetized PND-7 rats, using coordinates relative to bregma: anterior-posterior $-2.0 \mathrm{~mm}$. lateral $2.5 \mathrm{~mm}$, depth $4 \mathrm{~mm}$. One $\mu \mathrm{L}$ of the test compound(s), dissolved in $0.1 \mathrm{M}$ Tris- $\mathrm{HCl}$ or PBS, $\mathrm{pH} 7.4$, was injected over $5 \mathrm{~min}$ with a 26-gauge Hamilton syringe (13). These stereotaxic coordinates target dorsal hippocampus: the needle-tip placement often extends to posterior striatum. or thalamus, as a result of slight variations in animal size or injection angle. Animals were killed by decapitation on PND 12, and brains were removed quickly and frozen in dry ice. The animal use protocol was approved by the University of Michigan Committee on Animal Usage.

Histopathologic assessment. Twenty- $\mu \mathrm{m}$ coronal frozen brain sections, postfixed over paraformaldehyde vapors, were stained with cresyl violet. After injections of saline, the needle track is sometimes identifiable, but there is no adjacent cell loss or distortion of regional anatomy. Injections of NMDA $(5-25 \mathrm{nmol})$ elicit dose-dependent, reproducible, ipsilateral lesions in striatum, hippocampus, and cortex. At lower doses, selective neuronal necrosis is evident; at higher doses, marked substance loss is apparent $5 \mathrm{~d}$ after lesioning (13). Damage to overlying cortex likely results from leakage of NMDA along the needle track, rather than remote effects of NMDA. By PND 12, the extent of injury corresponds well with the severity of tissue damage detected at later time intervals. Subtle differences in the extent of injury resulting from injection of a specific NMDA dose in immature rodent brain may be related to slight differences in injection methods, animal age determination or usage, or ambient temperature.

Histopathology scores, based on light microscopy evaluation of $\geq 30$ Nissl-stained coronal sections through caudate and hippocampus/brain by an observer unaware of animal identity (F.S.S.), were defined as follows: 0 . no discernible lesion: 1 , lesion confined to cell loss in hippocampal pyramidal cell layer adjacent

Table 1. Summary' of experimental groups

Compound(s) administered by intracerebral injection

\section{NMDA (nmol)}

2.5

5

10

NMDA + env-gag

$2.5 \mathrm{nmol}+100 \mathrm{ng}$

$5 \mathrm{nmol}+1$ or $50 \mathrm{ng}$

$5 \mathrm{nmol}+100 \mathrm{ng}$

$10 \mathrm{nmol}+100 \mathrm{ng}$

Env-gag (ng)

1

50

100

Vector peptide (ng)

10

100

NMDA: $5 \mathrm{nmol}+$ vector peptide: $100 \mathrm{ng}$
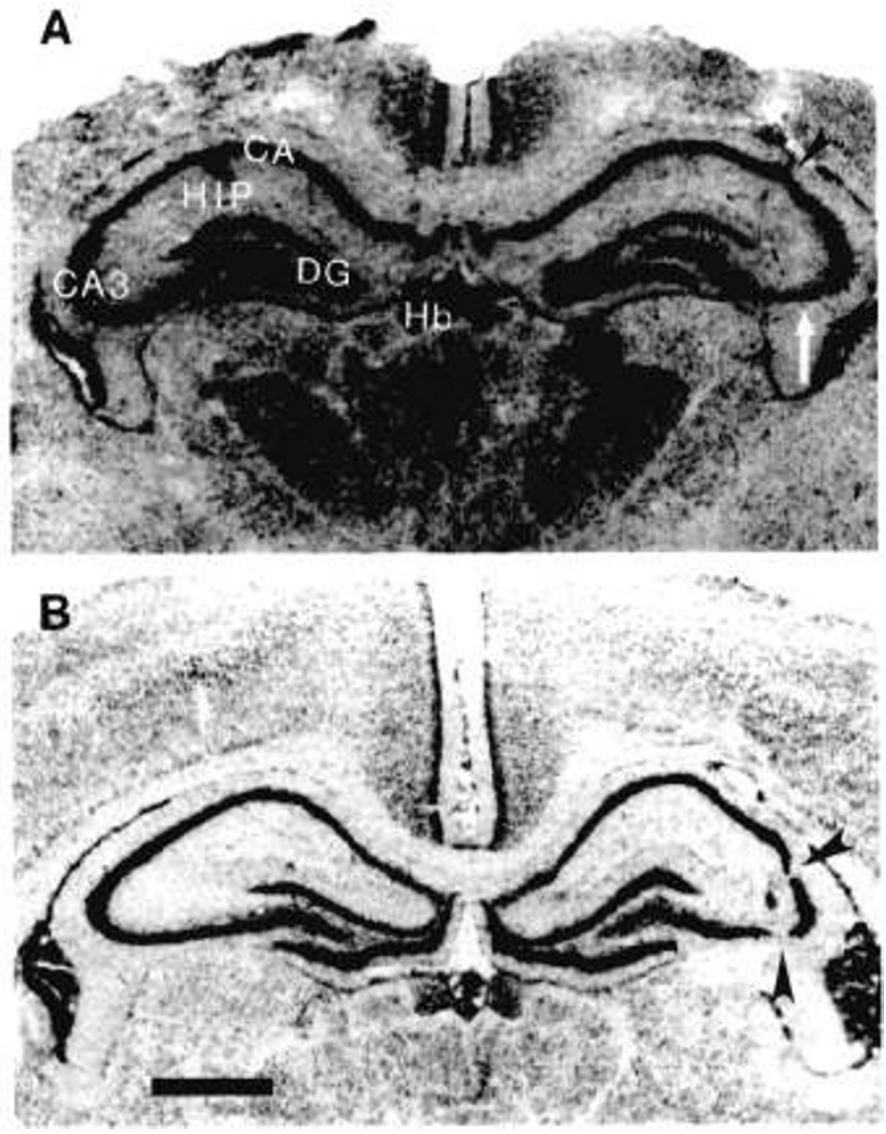

Fig. 1. Photographs of coronal brain sections at level of hippocampus $(H I P)$ and habenula $(H h)$, from two animals that received a right intracerebral injection of $5 \mathrm{nmol}$ of NMDA on PND 7 and were killed on PND 12. In panel $A$, the left hippocampus is normal; the cornu ammon $(C \cdot 1)$ represents the cell bodies of the hippocampal pyramidal cell layer, and the CA3 subfield is identified. $D G$ identifies the dentate gyrus. Two subtie abnormalities are evident in the right hippocampus: the black arrowhead identifies a defect in the pyramidal cell layer produced by the needle. with minimal adjacent cell loss. and the white arrow identifies a region of thinning of the pyramidal cell layer in CA3, along the path of the injection track (scored as 1 ). In panel $B$, the left hippocampus is normal: in the right CA3 subfield, there are two focal defects of the pyramidal layer (arrowheads), associated with the needle path (scored as 1) (scale har $=1 \mathrm{~mm})$.

to needle track: 2, more extensive hippocampal lesion with atrophy, and/or widespread pyramidal cell loss (most commonly in CA3); and 3, hippocampal lesion as in 2, together with evidence of injury extending to thalamus and/or caudate and/or septum.

Hippocampal cross-sectional areas were measured using a video camera-based computerized image analysis system (MCID, Imaging Research Inc., St. Catherines. Ontario, Canada). Measurements were obtained bilaterally from five or more serial sections per brain, at the level of the habenula, where hippocampal lesions were most often detected, by an individual unaware of animal identity. Although the sections measured did not always include the site of maximal injury (because of slight variations in needle placement), use of a standardized anatomic landmark minimized subjectivity in selection of areas to be compared. Because injury is incurred in a phase of rapid brain growth, interhemispheric discrepancies in brain mass reflecting both substance loss and impaired subsequent growth are quickly apparent, and comparison of bilateral regional cross-sectional areas provides a reliable measure of injury (13). Measures based on comparisons of interhemispheric differences take into account 

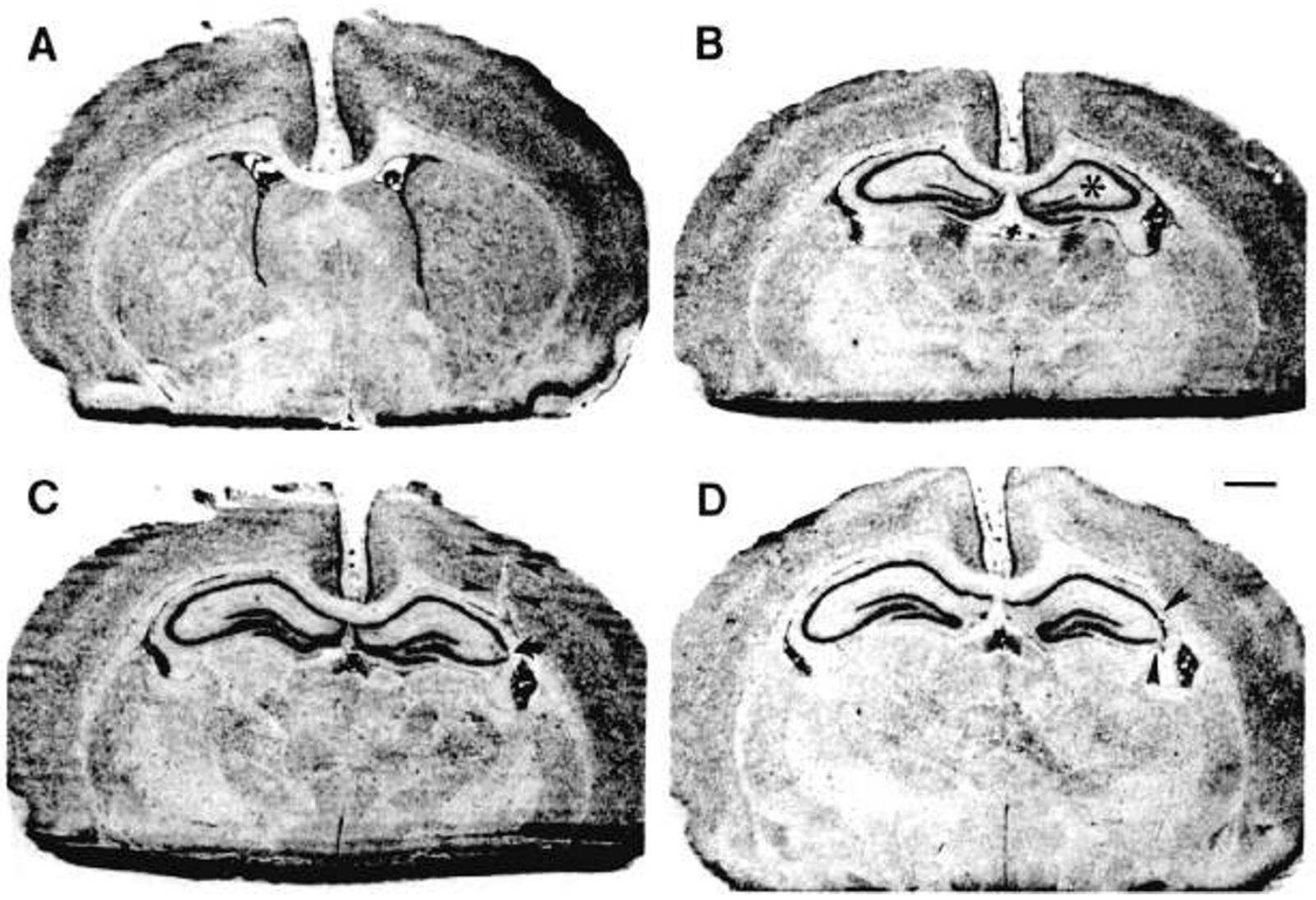

Fig. 2. Photographs of four sequential coronal sections, prepared from the brain of an animal that received a right intracerebral injection of 5 nmol NMDA + 50 ng env-gag on PND 7 (see Materials and Methods) demonstrate the major features of a moderate severity lesion (scored 2). In panel $A$, there is no evidence of right striatal atrophy or ventricular dilatation. In panel $B$, there is atrophy of the right hippocampus $(*)$, anterior to the injection site. In panel $C$, the needle path through cortex is evident (arrowheads). There is subtle atrophy of the right hippocampus, and there is focal loss of CA3 pyramidal neurons adjacent to the injection path (curved arrow'). In panel $D$, posterior to the injection site, there is persistent right hippocampal atrophy and thinning of CA3 pyramidal layer (arrowheads, scale bar $=1 \mathrm{~mm}$ ).

slight variations in animal size, sites of injection, and differences in tissue fixation.

Experimental protocols. Table 1 summarizes the treatment groups included in this study.

In preliminary experiments, env-gag, 1 to $100 \mathrm{ng}(0.02-2.4$ pmol), dissolved in $1 \mu \mathrm{L} 0.1 \mathrm{M}$ Tris- $\mathrm{HCl}$ or PBS, $\mathrm{pH} 7.4$, were injected intracerebrally into PND-7 rats, and animals were killed on PND 12. No behavioral changes were noted acutely, and there was no postoperative mortality. In animals that received 1 or $50 \mathrm{ng}$, no neuropathologic lesions were observed ( $1 \mathrm{ng}, n=3$; $50 \mathrm{ng}, n=3)$. In animals that received $100 \mathrm{ng}(n=7)$, focal pyramidal cell loss was detected in the hippocampus adjacent to the injection track. Body temperature was monitored intermittently (with an electronic thermometer) for $2 \mathrm{~h}$ after intracerebral injection of $100 \mathrm{ng}$ of env-gag in four of these animals and in four animals that received an equal volume of saline; mean temperatures were the same in both groups.

Next, PND-7 rats received intrastriatal injections of $2.5 \mathrm{nmol}$ of NMDA [a dose that typically elicits no histopathologic lesions (13)] alone or coinjected with env-gag (100 ng) $(n=5)$; all animals survived. No lesions were detected in animals that received NMDA alone $(n=3)$; subtle hippocampal lesions (e.g. disruption of the pyramidal cell layer adjacent to the needle track) were detected in two of four animals given coinjections of env-gag. In a group of animals that received $10 \mathrm{nmol}$ of NMDA alone or in coinjections with env-gag $(100 \mathrm{ng})$, there was extensive tissue injury ipsilaterally in all animals (which precluded analysis of potentiation of toxicity). Thus, an intermediate NMDA dose, $5 \mathrm{nmol}$, was selected for subsequent experiments. The maximal dose of env-gag selected for testing was based on the concentration of the available preparation; two doses were selected initially, 1 and $100 \mathrm{ng}$, and the 50-ng env-gag dose was included in later experiments, after a high mortality rate was encountered in animals that had been given coinjections of 5 nmol of NMDA and $100 \mathrm{ng}$ of env-gag.

The 67 animals used to assess histopathology were derived from 10 experiments. Each experiment included "NMDA alone" and "NMDA+env-gag"-injected animals; however, it was not feasible to use a paired design because of factors such as perioperative mortality, injection inaccuracies, and artifactual tissue distortion. Of 81 animals, eight died postoperatively $(1 \mathrm{~h}$ to $5 \mathrm{~d}$ later; NMDA alone, $n=1$; NMDA +1 ng env-gag, $n=2 ; 5$ nmol NMDA + $100 \mathrm{ng}$ env-gag, $n=5$ ), and six brains were excluded from analysis, based on injection inaccuracy or histopathologic artifact.

The neurotoxicity of the 21 -amino acid $E$. coli plasmid-derived vector peptide, used for expression of env-gag, was also tested as a control for potential vector-derived effects, alone (10 $\mathrm{ng}, n=$ $3 ; 100 \mathrm{ng}, n=3)$ and coinjected with $5 \mathrm{nmol}$ of NMDA $(n=4)$. The vector peptide did not cause injury or influence NMDAmediated injury.

Data analysis. Brains were excluded from analysis if freezing artifact caused asymmetric tissue distortion or mechanical disruption of tissue or if the needle track was clearly misplaced.

A microcomputer-based software program (Statview II, Abacus, Berkeley, CA) was used for statistical analysis. Animals that died postoperatively, before PND 12, were excluded from analysis. Preliminary descriptive statistics indicated that histopathology scores for NMDA + $1 \mathrm{ng}$ env-gag and NMDA + $50 \mathrm{ng}$ envgag groups did not differ, and animals that received these two treatments were subsequently grouped for further analysis. Histopathology scores in animals that received $5 \mathrm{nmol}$ NMDA 

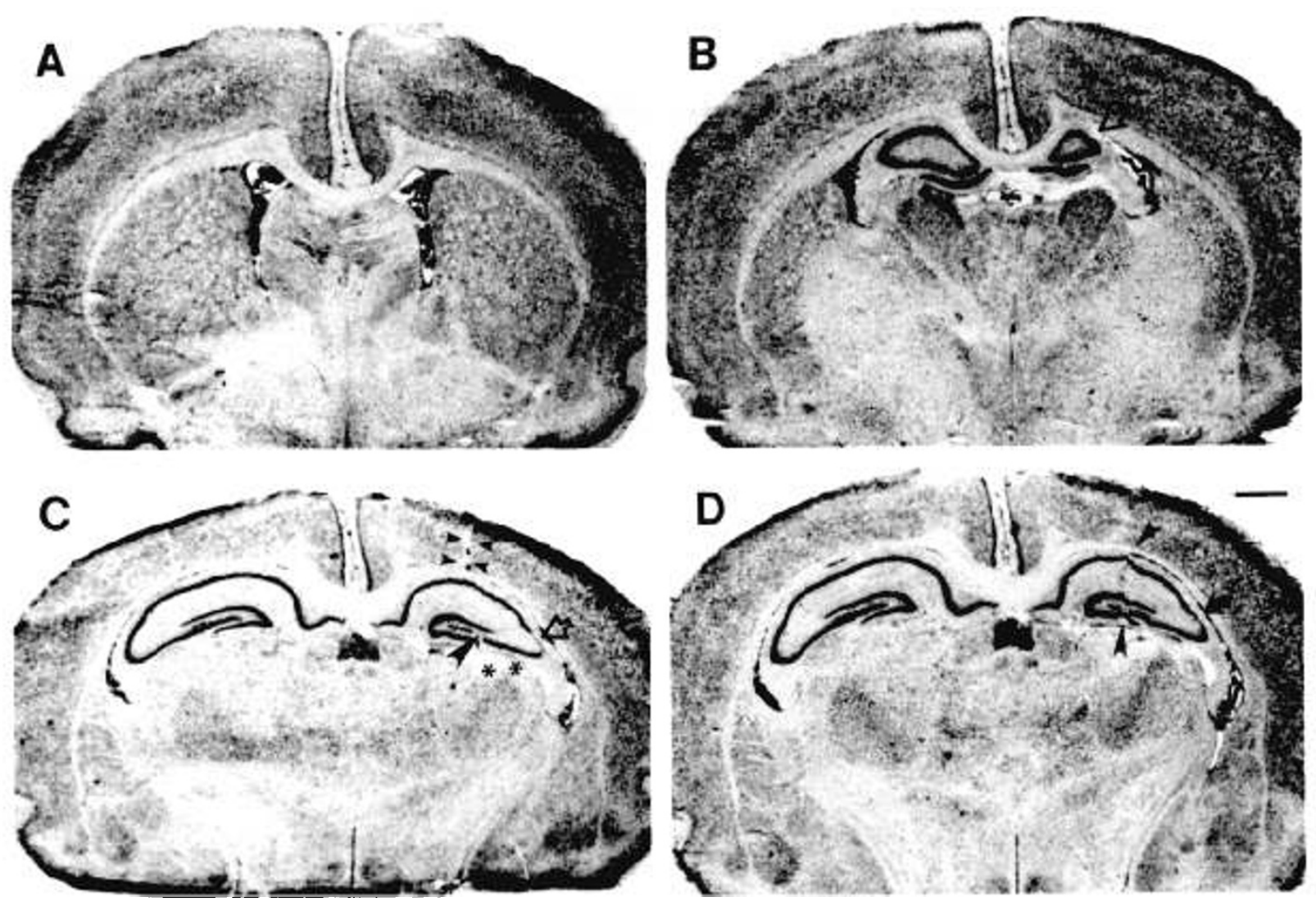

Fig. 3. Photographs of four sequential coronal sections, prepared from the brain of an animal that received a right intracerebral injection of 5 nmol NMDA + 100 ng env-gag on PND 7 (see Materials and Methods) demonstrate the major features of a more extensive lesion (scored 3). In this animal, there was a relatively posterior injection track. In panel $A$. there is no striatal atrophy or ventricular dilatation. In panel $B$. there is atrophy of the tip of the right hippocampus (open arrow) anterior to the injection site. In panel $C$, the injection track can be identified in the cortex (small arrowheads) and hippocampal CA4 subfield (large arrow'head). Right hippocampal atrophy is prominent. including marked thinning of CA3 pyramidal layer (open arrow), remote from the injection path. Injury in the right thalamus is also evident $\left(^{* *}\right)$. In panel $D$. more posteriorly. the injection path (arrowheads) is identifiable, and prominent right hippocampal atrophy and CA3 pyramidal layer thinning (curved arrow) are evident ( scale bar $=1 \mathrm{~mm}$ ).

alone, $5 \mathrm{nmol} \mathrm{NMDA}+1$ or $50 \mathrm{ng}$ env-gag, and $5 \mathrm{nmol}$ NMDA $+100 \mathrm{ng}$ env-gag were compared with a nonparametric ranking test (Kruskal-Wallis test). Left and right hippocampal areas, as well as interhemispheric differences, in these three groups were compared by one-way analysis of variance.

\section{RESULTS}

To assess the influence of coinjection of env-gag on NMDA neurotoxicity, histopathology was assessed in sections prepared from 67 animals ( $5 \mathrm{nmol}$ NMDA, alone, $n=20$; with 1 or 50 ng env-gag, $n=27$; or with $100 \mathrm{ng}$ env-gag, $n=20$ ). There were no consistent behavioral differences among groups. There was a substantial rise in acute mortality in animals that received the highest dose of the peptide (100 ng) (five of 13 died within $1 \mathrm{~h}$ postinjection in the first two experiments). Later deaths occurred in one of eight animals that received NMDA alone and in two of eight that were given coinjections of $1 \mathrm{ng}$ of env-gag.

Histopathology. Pathologic lesions were recognized in 56 of 67 survivors examined on PND 12. The most subtle lesion, discrete neuronal cell loss adjacent to the needle track, was most commonly detected in the pyramidal cell layer near the junction of CA1 and CA3, and in the overlying cortex (Fig. 1). Typically, in lesions related to the needle track, at least two anatomic defects, with the same perpendicular alignment to the cortical surface, were apparent on three or more adjacent sections. Features of more severe hippocampal lesions included relative preservation of CA 1 and dentate gyrus neurons, together with prominent cell loss in CA3 (remote from the injection track); the same pattern of selective vulnerability is evident after injections of higher doses of NMDA alone (Barks and Silverstein, unpublished observation).

In addition, in the more severely lesioned brains, hippocampal atrophy, reflecting injury to the dendritic arbor, was often much more prominent than pyramidal cell loss (Fig. 2-4). Figure 2 presents sequential sections from a single brain demonstrating the features of a moderate severity lesion (scored 2): major features of the lesion, which is limited to the hippocampus, include subtle ipsilateral atrophy (panels $B-D$ ), focal cell loss adjacent to the track (panels $C$ and $D$ ), and subtle CA 3 cell loss, extending from the injection track. Figures 3 and 4 present sequential sections from two brains that demonstrated more extensive lesions (scored 3). In Figure 3, panel $C$ demonstrates the major features of the lesion: in addition to hippocampal cell loss and atrophy, there is injury to the adjacent underlying thalamus. In Figure 4, the major features of the lesion, reflecting a somewhat more anterior injection, include prominent striatal atrophy and corresponding ventricular dilatation ( panel $A$ ), together with hippocampal atrophy ( panels $B$ and $C$ ); in this brain, hippocampal cell loss (e.g. in panel $D$ ) is again less prominent than is atrophy. In Figure 5, higher power views of the lesioned hippocampus, from the same brains as presented in Figures 2 and 3, provide more detailed features of hippocampal histopathology. Cortical lesions were not used for scoring: in those brains with extensive cortical lesions, there were also lesions in caudate and/or thalamus.

Comparison of the distributions of histopathology scores in 

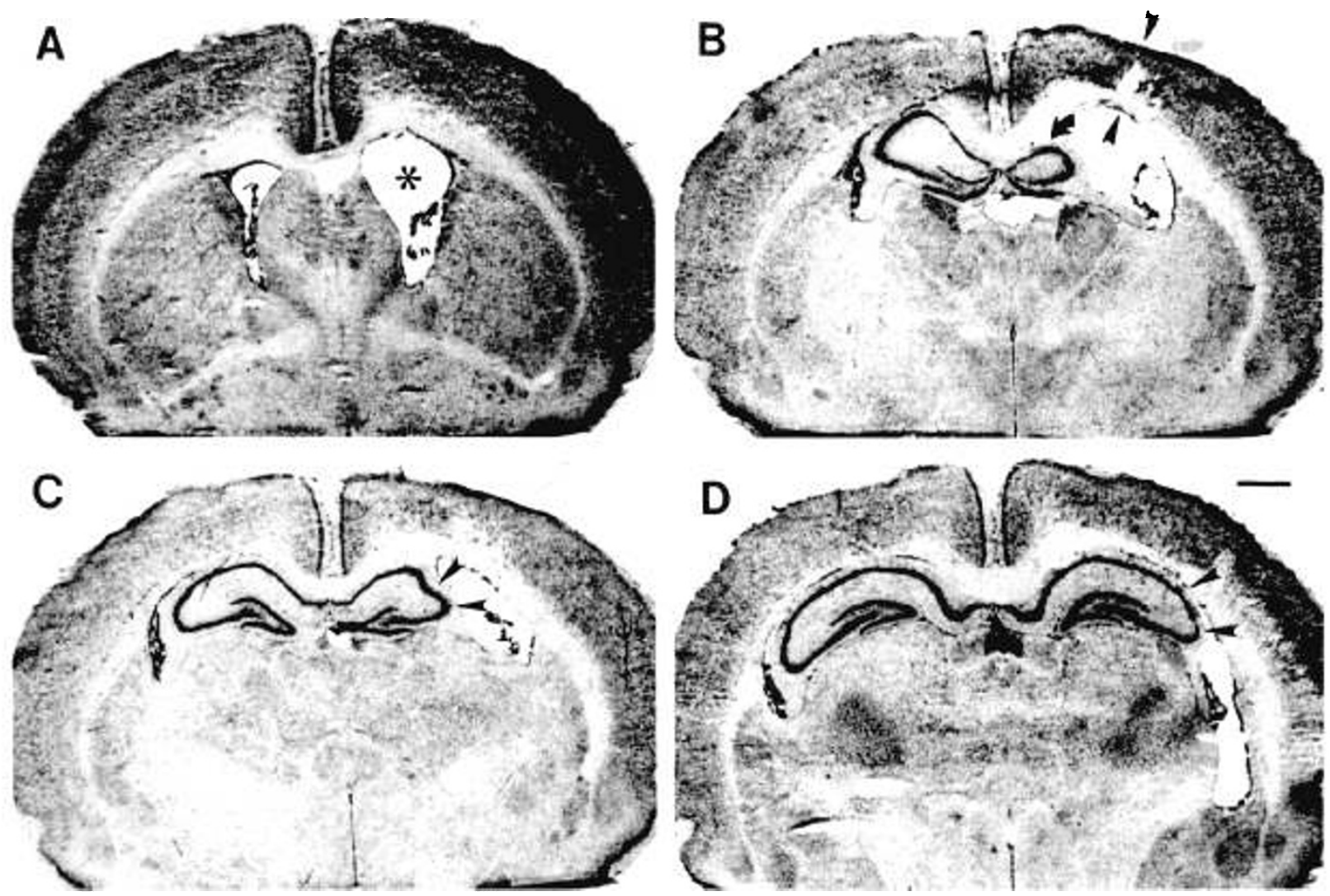

Fig. 4. Photographs of four sequential coronal sections, prepared from the brain of an animal that received a right intracerebral injection of 5 nmol NMDA + 100 ng env-gag on PND 7 (see Materials and Methods) demonstrate the major features of an extensive lesion (scored 3). In this animal, the injection track was relatively anterior. In panel $A$, there is right striatal atrophy and compensatory ventricular dilatation $\left({ }^{*}\right)$. In panel $B$, at the level of the injection track (arrowheads), the anterior right hippocampus is atrophied (curved arrow). In panel $C$, there is right hippocampal atrophy, predominantly of CA3 subfield (arrowheads). In panel $D$, more posteriorly, thinning of the CA3 pyramidal layer is evident, along with more subtle hippocampal atrophy (scored as 3$)$ (scale har $=1 \mathrm{~mm}$ ).

the three groups revealed significant treatment effects, consistent with the hypothesis that env-gag potentiates the neurotoxic properties of NMDA in vivo: the most severe lesions were detected most frequently in the animals that received $5 \mathrm{nmol}$ NMDA + $100 \mathrm{ng}$ env-gag $(p<0.002$, Kruskal-Wallis test, corrected for ties, Fig. 6). Although the most severe lesions evolved in animals given coinjections of the highest env-gag dose, there were no differences in the severity of injury between animals given coinjections of 1 or $50 \mathrm{ng}$ of env-gag.

Hippocampal cross-sectional area measurements. In the three groups, the mean left hippocampal areas did not differ, whereas there was a progressive reduction in right hippocampal area (Table 2. This pattern of progressive hippocampal atrophy is also elicited by increasing doses of NMDA; substance loss reflects injury to the pyramidal cell dendritic arbor (which has a high density of NMDA receptors). Comparison of interhemispheric differences in hippocampal areas in animals from the three groups indicated that ipsilateral hippocampal atrophy was greatest in animals that received NMDA + $100 \mathrm{ng}$ env-gag (NMDA alone: $-10.2 \pm 2.7 \%$; mean \pm SEM; NMDA + 1/50 ng env-gag: $-13.1 \pm 2.7 \%$; NMDA + 100 ng env-gag: $-24.9 \pm 3.4 \% ; p<$ 0.003 , analysis of variance).

\section{DISCUSSION}

A large body of experimental evidence indicates that overactivation of the NMDA-type EAA receptor contributes to irreversible neuronal injury in a variety of neurologic disorders (14). Possible molecular mechanisms underlying HIV peptide-mediated potentiation of EAA agonist-mediated neurotoxicity include direct agonist effects at EAA recognition sites or at one of the allosteric regulatory sites of the NMDA receptor (15), or suppression of presynaptic EAA reuptake activity. Alternatively, because NMDA-mediated neuronal damage results, in large part, from overwhelming rises in intracellular calcium, env-gag's potentiation of NMDA toxicity could be mediated by increased intracellular calcium accumulation (e.g. because of increased permeability of cation channels, increased release from intracellular stores, or reduced capacity of mitochondria to buffer intracellular calcium), as may be relevant for gp 120 . The only other identified experimental interventions that augment NMDA-mediated injury in perinatal rodents are hyperthermia, presumably as a result of energy failure in neurons with increased metabolic demands, and hyperbilirubinemia, which may result from mitochondrial injury $(16,17)$.

Two recent studies suggest that other HIV proteins may be neurotoxic in vivo. Intracerebroventricular injection of $\mathrm{gp} 120$ in adult rats resulted in functional disruption of energy metabolism with global reductions in cerebral metabolic rate for glucose (18), in animals killed 45 min postinjection. Because glucose-deprived cells are more susceptible to NMDA-induced injury (19), gp 120induced disruption of neuronal glucose metabolism also suggests another pathophysiologic mechanism whereby an HIV protein could aggravate EAA-mediated neurotoxicity. More surprising were the findings in a recent study examining the bioactivity of a peptide derived from the regulatory HIV gene "tat"; intraventricular injection of a tat fragment induced acute neurologic abnormalities and caused rapid death which was attributed to CNS dysfunction in mice, but no tat-related neuropathologic lesions were identified (20).

It is relevant to note that the best-defined bioactivity of envgag is immunoregulatory (9), and it is conceivable that intracer- 


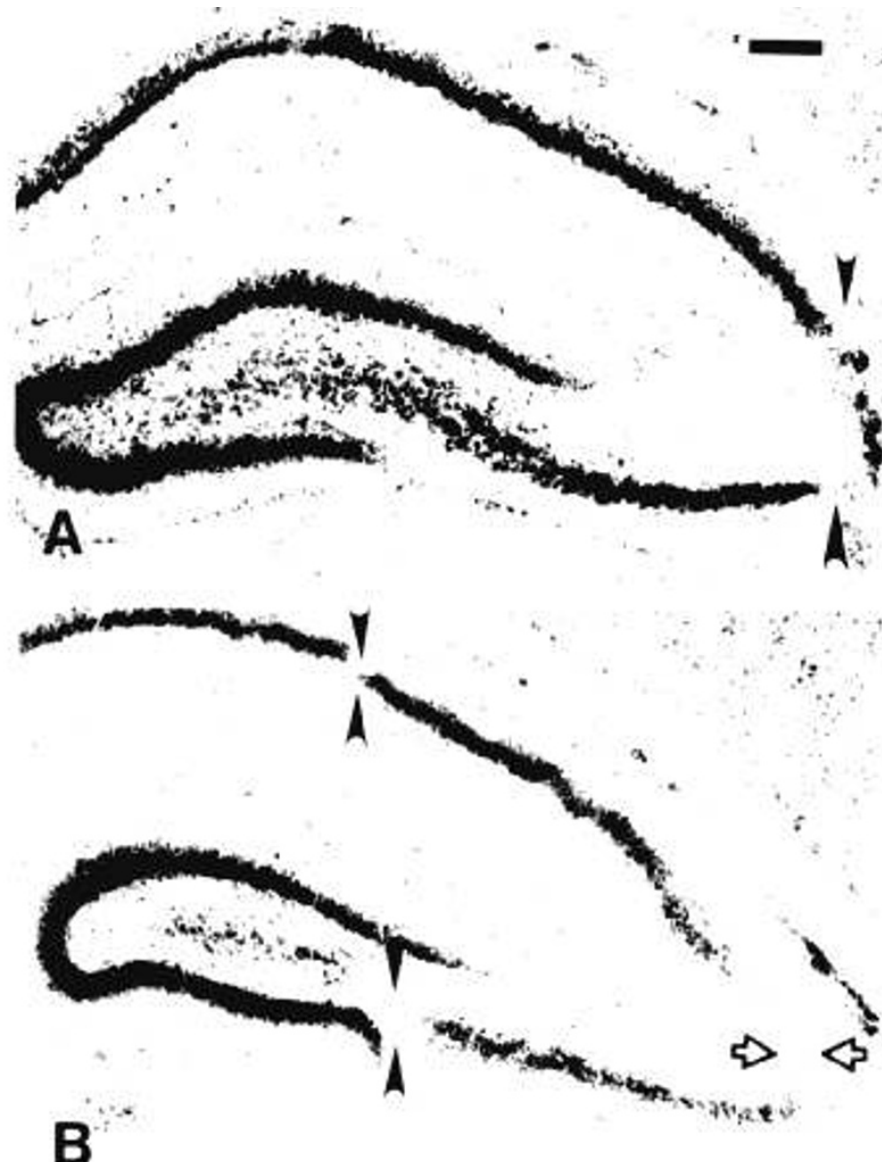

Fig. 5. Photographs of hippocampus from the same brains as presented in Figures 2 and 3, at higher magnification, to demonstrate the extent of cell loss in the pyramidal cell layer. In panel $A$, from an animal that received $5 \mathrm{nmol}$ NMDA $+50 \mathrm{ng}$ env-gag (see Fig. 2), the black arrowheads identify the two regions of cell loss, extending from the needle track. In panel $B$, from an animal that received $5 \mathrm{nmol}$ NMDA +100 ng env-gag (see Fig. 3), the hlack arrowheads identify the two regions of cell loss (in CAl and in CA4), extending from the needle track: open arrous identify a region of prominent pyramidal cell loss in CA3, remote from the injection track (scale har $=200 \mu \mathrm{m}$ ).

ebral injection of the HIV peptide stimulated induction of immune mediators that, in turn, elicited the observed neurotoxic effects. Intracerebral injection of gp120 in adult rats stimulated IL-1 bioactivity (21); however, because NMDA itself may induce cytokine production in brain (Silverstein F, unpublished observation), it will be difficult to address this question experimentally.

Whether HIV directly infects neurons has been a subject of controversy; HIV epitopes have now been identified in brains of patients with AIDS (22), and evidence from fetal tissue indicates that HIV crosses the placenta and directly invades the CNS (23). In patients with AIDS, potential mechanisms of HIV-induced neurologic dysfunction include direct infection of glia and neurons, release of soluble factors from HIV-infected macrophages, stimulation of cytokine production, or induction of autoimmunity. Typical neuropathologic features of CNS AIDS include predominant subcortical damage, with macrophage infiltration, reactive gliosis, white matter pallor, and characteristic microglial nodules with multinucleated giant cells (24). Cortical thinning, with loss of neurons and synaptic markers, were recently demonstrated (24), and HIV-EAA interactions may be most relevant to the pathogenesis of this type of injury (25).

Several clinical observations may also be important for understanding the complex mechanisms of HIV neurotoxicity. In children with CNS AIDS, cognitive functioning may improve

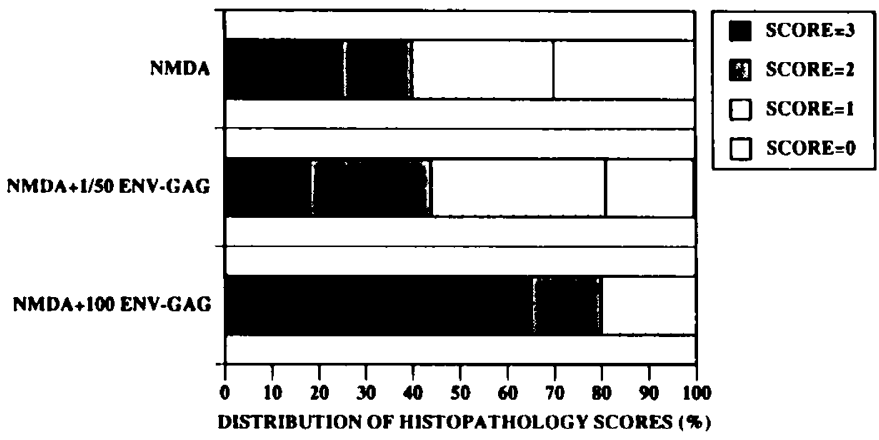

Fig. 6. Comparison of distributions of histopathology scores in 67 animals from three treatment groups. On PND-7, animals received right intracerebral injections of $5 \mathrm{nmol}$ of NMDA alone or were given coinjections of 1. 50, or $100 \mathrm{ng}$ env-gag. Histopathology was assessed, using an arbitrary four-point (0-3) scale on PND 12 (see Materials and Methods). After preliminary analysis revealed that scores for animals given coinjections of 1 or $50 \mathrm{ng}$ env-gag did not differ. the results in the two groups were combined for further analysis. The frequency of the most severe lesions was highest in animals that had received NMDA + $100 \mathrm{ng}$ env-gag $(p<0.002$. comparing scores in the three groups with the Kruskal-Wallis ranking test). If animals that died postoperatively were included in the analysis, and scored as most severely lesioned. results demonstrated the same trends in outcome differences among the three groups. There were no significant differences between the scores of animals that received NMDA alone or NMDA + 1 or $50 \mathrm{ng}$ env-gag.

Table 2. Comparison of hippocampal areas in lesioned animals*

\begin{tabular}{|c|c|c|c|c|}
\hline \multirow[b]{2}{*}{ Treatment } & \multicolumn{3}{|c|}{ Area $\left(\mathrm{mm}^{2}\right)$} & \multirow{2}{*}{$\begin{array}{c}\text { Interhemispheric } \\
\text { difference }(\%) \S\end{array}$} \\
\hline & $n$ & Left + & Right $\ddagger$ & \\
\hline 5 NMDA & 20 & $4.6 \pm 0.1$ & $4.1 \pm 0.1$ & $-10 \pm 3$ \\
\hline $\begin{array}{l}5 \text { NMDA + } 1 \text { or } \\
50 \text { env-gag }\end{array}$ & 27 & $4.5 \pm 0.1$ & $3.9 \pm 0.1$ & $-13 \pm 3$ \\
\hline 5 NMDA + 100 env-gag & 20 & $4.7 \pm 0.1$ & $3.6 \pm 0.2$ & $-25 \pm 3$ \\
\hline
\end{tabular}

* Regional cross-sectional areas of hippocampus were measured at the level of habenula (see Materials and Methods and Fig. 1) in animals that received right intracerebral injections of $5 \mathrm{nmol}$ of NMDA. together with 0. 1. 50, or $100 \mathrm{ng}$ of env-gag on PND 7 and were killed on PND 12. Values from animals given coinjections of 1 or $50 \mathrm{ng}$ of env-gag did not differ and were grouped together for analysis. Values are means \pm SEM.

$\dagger p=$ NS. comparing left hippocampal areas by analysis of variance.

$\ddagger p<0.04$, comparing right hippocampal areas by analysis of variance.

$\$$ Interhemispheric differences were calculated as the means of differences in bilateral hippocampal areas in each animal of each group. $p<$ 0.003 . comparing interhemispheric differences by analysis of variance.

after treatment with azidodeoxythymidine (26), this suggests that neurologic symptoms may, in part, reflect functional disruption. e.g. by toxic/metabolic factors, rather than irreversible neuronal damage. HIV-derived peptides, with specific modulatory actions at EAA synapses, could represent such toxic factors. Clinical data suggest an additional mechanism whereby EAA receptor activation could contribute to HIV neurotoxicity; elevated concentrations of quinolinate, a tryptophan metabolite with NMDA agonist properties, have been detected in CSF of patients with CNS AIDS (27). If quinolinate concentrations were chronically elevated in HIV-infected brains, this could contribute to sustained overactivation of NMDA receptors, and result in functional and/or structural disruption of susceptible neurons.

Several important limitations in assessing the relevance of our findings to HIV infection in humans must be considered. It is difficult to estimate the concentrations of the peptide attained in brain and the duration of exposure. The experimental paradigm of concurrent exposure to the HIV peptide and the NMDA agonist clearly does not replicate the temporal sequence likely to be encountered in HIV-infected patients: yet the data suggest 
that this approach yields pathophysiologically relevant results. Also, it is quite likely that maturational stage will influence susceptibility to HIV-mediated neurotoxicity. These experiments were restricted to PND-7 rats, based on the detailed characterization of the histopathology of excitotoxic injury at this age. coupled with the coincidence of the ontogenetic peak of susceptibility to NMDA-induced injury and ease of rapid quantitative analysis of injury during this phase of rapid brain growth. Estimates, based on brain growth rates, suggest that the PND-7 rat brain is comparable to the term human infant brain (28). The issue of species specificity must also be acknowledged, and the extent to which results of experiments performed in perinatal rodent brain are applicable to the human infant is uncertain. Although HIV encephalopathy does not occur in rodents, rodent models of excitotoxic injury may well be relevant to understanding human neuropathology (29). It must also be acknowledged that it is conceivable that the recombinant fusion peptide possesses intrinsic neurotoxic properties that neither of the parent peptides possesses, and additional studies will be essential to identify the neurotoxic moiety of env-gag.

A large body of experimental data indicates that a variety of pathophysiologic insults, e.g. cerebral ischemia and hypoglycemia, increase synaptic accumulation of EAA (because of greater release and/or suppression of reuptake) during the evolution of injury $(14,30)$. Thus, if HIV peptides potentiate EAA-mediated neuronal injury in vivo in the human brain, HIV-infected infants may be more susceptible to neuronal damage from cerebral ischemia, hypoglycemia, and related metabolic disorders. The severity and rate of progression of CNS disease vary widely in HIV-infected infants. Many HIV-infected neonates also incur asphyxial insults, hypoglycemia, and exposure to potentially neurotoxic drugs; the extent and mechanism(s) by which such adverse events influence progression of HIV infection are unknown. Nor is it known if susceptibility to HIV neurotoxicity is influenced by specific developmental features, expressed in the fetus and infant brain. It is interesting to consider that lesions of the basal ganglia, a major target region for ischemic injury in the developing brain, are often noted in infants with congenital HIV infection; whether perinatal ischemia enhances susceptibility to HIV-induced basal ganglia degeneration in HIV-infected infants is unknown. Understanding mechanisms of HIV neurotoxicity in the perinatal brain will hopefully provide the scientific foundation for development of more effective therapeutic interventions for HIV-infected infants.

Acknowledgments. The authors thank Dr. Rong Sun for able technical assistance.

\section{REFERENCES}

1. Ehrnst A, Lindgren S, Dictor M 1991 HIV in pregnant women and their offspring: evidenre for late transmission. Lancet 338:203-207

2. Belman AL, Ultmann M, Kurtzberg D. Cone-Wesson B 1985 Neurological complications in children with AIDS. Ann Neurol 18:560-566

3. Dreyer FB, Kaiser PK, Offermann JT, Lipton SA 1990 HIV-1 coat protein neurotoxicity prevented by calcium channel antagonists. Science $248: 364-$ 367

4. Giulian D, Vaca K, Noonan CA 1991 Secretion of neurotoxins by mononuclear phagocytes infected with HIV-1. Science 250:1593-1596

5. Pulliam L, Herndier BG, Tang NM, McGrath MS 1991 Human immunodeficiency virus-infected macrophages produce soluble factors that cause histological and neurochemical alterations in cultured human brains. J Clin Invest 87:503-512
6. Lipton SA. Sucher NJ. Kaiser PK. Drever EB 1991 Synergistic effects of HIV coat protein and NMDA receptor mediated neurotoxicity. Neuron 7:111118

7. Lipton, SA 1992 Models of neuronal injury in AIDS: another role for the NMDA receptor? Trends Neurosci 15:76-80

8. McDonald JW, Silverstein FS, Johnston MV 1988 Neurotoxicity of NMDA is markedly enhanced in developing rat central nervous system. Brain Res 459:200-203

9. Nair MPN. Pottathil R, Heimer EP. Schwartz SA 1988 Immunoregulatory activities of HIV proteins: effect of HIV recombinant and synthetic peptides on immunoglobulin synthesis and proliferative responses by normal lymphocytes. Proc Natl Acad Sci USA 85:6498-6502

10. Luzzati AL, Pugliese O. Giacomini E, Giordani L, Quineri F, Hraba T, Mach V. Krchnak V, Vagner J 1990 Immunoregulatory effect of a synthetic peptide corresponding to a region of protein p24 of HIV. Folia Biol 36:71-77

11. Shulaby MR. Krowka JF, Gregory TJ 1989 The effects of HIV recombinan envelope glycoprotein on immune cell functions in vitro. Cell Immunol 110:140-148

12. Weinhold KF. Lyerly HK. Stanley. SD. Austin AA. Mathews TJ. Bolognes DP 1989 HIV-1 gp120 mediated immunosuppression and lymphocyte destruction in the absence of viral infection. J Immunol 142:3091-3097

13. McDonald JW, Roeser NF. Silverstein FS, Johnston MV 1989 Quantitative assessment of neuroprotection against NMDA-induced brain injury. Exp Neurol 106:289-296

14. Choi DW, Rothman SM 1990 The role of glutamate neurotoxicity in hypoxicischemic neuronal death. Ann Rev Neurosci 13:171-182

15. Reynolds IJ, Miller RJ 1990 Allosteric modulation of NMDA receptors. Adv Pharm 21:101-126

16. McDonald JW. Shapiro SM. Silverstein FS. Johnston MV 1990 Hyperbilirubinemia is associated with enhanced susceptibility to excitotoxic brain injury. Soc Neurosci Abstr 16:461(abstr)

17. McDonald JW. Chen CK. Trescher WH, Johnston MV 1991 The severity of excitotoxic brain injury is dependent on brain temperature in immature rat. Neurosci Lett 126:83-86

18. Kimes AS, London ED, Szabo G. Raymon L. Tabakoff B 1991 Reduction of cerebral glucose utilization by the HIV envelope glycoprotein-Gp-120. Exp Neurol 112:224-228

19. Novelli A. Reilly JA. Lysko PG. Henneberry RC 1988 Glutamate becomes neurotoxic via the $N$-methyl-D-aspartate receptor when intracellular energy levels are reduced. Brain Res 451:205-212

20. Sabatier JM. Vives E. Mabrouk K. Benjouad A. Rochat H, Duval A, Hue B. Bahraoui E 1991 Evidence for neurotoxic activity of tat from HIV type 1. J Virol 65:961-967

21. Sundar SK. Cierpial MA. Kamaraju LS, Long S, Hsieh S, Lorenz C. Aaron M. Ritchie JC. Weiss JM 1991 Human immunodeficiency virus glycoprotein (GP120) infused into rat brain induces interleukin 1 to elevate pituitaryadrenal activity and decrease peripheral cellular immune responses. Proc Natl Acad Sci USA 88:11246-11250

22. Kure K. Weidenheim KM. Lyman WD. Dickson DW 1991 Morphology and distribution of HIV-1 gp41-positive microglia in subacute AIDS encephalitis Pattern of involvement resembling a multisystem degeneration. Acta Neuropathol 80:393-400

23. Lyman WD Soeiro R, Rashbaum WK 1990 HIV-1 infection of human fetal central nervous system tissue. In: Kozlowski PB. Snider DA.Vietze PM, Wisniewski HM (eds). Brain in Pediatric AIDS. Karger. Basel, pp 183-196

24. Wiley CA, Schrier RD. Nelson JA 1986 Cellular localization of human immunodeficiency virus infection within the brain of acquired immune deficiency syndrome patients. Proc Natl Acad Sci USA 83:7089-7093

25. Wiley CA. Masliah E, Morey M. Lemere C, DeTeresa R. Grafe M. Hansen L. Terry $R$ 1991 Neocortical damage during HIV infection. Ann Neurol 29:651-657

26. Pizzo PA. Eddy J. Falloon J. Balis FM. Murphy RF, Moss H. Wolters P. Brouwers P. Jarosinski P. Rubin M 1988 Effect of continuous intravenous infusion of zidovudine (AZT) in children with symptomatic HIV infection. N Engl J Med 319:889-896

27. Heyes MP, Rubinow D. Lane C. Markey SP 1989 Cerebrospinal fluid quinolinic acid concentrations are increased in acquired immune deficiency syndrome. Ann Neurol 26:275-277

28. Dobbing J. Sands J 1979 Comparative aspects of the brain growth spurt. Early Human Dev 3:79-83

29. Stewar GR Zorumski CF, Price MT, Olney JW 1990 Domoic acid: a dementia-inducing excitotoxic food poison with kainic acid receptor specificity. Exp Neurol 110:127-138

30. Silverstein FS, Naik B. Simpson J 1991 Hypoxia-ischemia stimulates hippocampal glutamate efflux in perinatal rat brain: an in vivo microdialysis study. Pediatr Res 30:587-591 